\title{
PARÂMETROS E INDICADORES DA QUALIDADE DA ÁGUA NO RIACHO DO OURO, CAXIAS, MARANHÃO
}

\author{
Jailson da Costa Gaspar ${ }^{1}$, Gonçalo Mendes da Conceição ${ }^{2}$
}

1. Graduando em Ciências Biológicas Licenciatura, CESC/UEMA, Laboratório de Biologia Vegetal/LABIVE, Caxias/MA, Brasil. (jailsoncosta18@hotmail.com)

2. Professor Dr. do Centro de Estudos Superiores de Caxias/CESC, da Universidade Estadual do Maranhão/UEMA, Professor do Programa de Pós-Graduação em Biodiversidade, Ambiente e Saúde/PPGBAS, Maranhão/Brasil

Recebido em: 08/04/2017 - Aprovado em: 10/06/2017 - Publicado em: 20/06/2017 DOI: 10.18677/EnciBio_2017A114

\begin{abstract}
RESUMO
No município de Caxias/Maranhão encontra-se a bacia hidrográfica do Rio Itapecuru, com vários riachos submetidos a ação antropogênica, com visível contaminação por esgotos, desmatamento marginais, queimadas, assoreamento e descumprimento às leis ambientais. Objetivou-se com a realização do presente estudo avaliar a qualidade da água do Riacho Ouro no município de Caxias/MA, através da análise dos parâmetros físicos e químicos, para a determinação do seu enquadramento e sua adequabilidade para seus diversos usos. Foram realizadas duas coletas em oitos pontos pré-definidos no período seco, avaliados através da análise de quatorze parâmetros de qualidade: físicos (temperatura, $\mathrm{pH}$, condutividade, cor verdadeira, turbidez, sólidos totais e dissolvidos) e químicos (nitrito, nitrato, nitrogênio amoniacal, fósforo total, alcalinidade, ferro e dureza total) e comparados com a resolução do CONAMA 357/05. Constatou-se que as águas do riacho do Ouro encontram-se com $\mathrm{pH}$ levemente ácido, podendo ser influenciado pela decomposição da matéria orgânica no leito do riacho. Os parâmetros alcalinidade total e ferro dissolvido de acordo com as referências ficaram fora do limite de aceitação. O teor de fósforo total mostrou-se acima da especificação, provavelmente em decorrência das atividades agrícolas realizadas na área. O nitrogênio com suas diferentes formas indicam que o riacho do Ouro está livre de alguns poluentes que interferem na qualidade da água e na vida da comunidade aquática e da população ribeirinha.
\end{abstract}

PALAVRAS-CHAVE: Degradação ambiental, Recursos hídricos, Poluição aquática.

\section{WATER QUALITY PARAMETERS AND INDICATORS IN THE GOLDEN WATER, CAXIAS, MARANHAO}

\footnotetext{
ABSTRACT

In the municipality of Caxias / Maranhão, there is the Itapecuru River basin, with several streams submitted to anthropogenic action, with visible contamination by sewage, marginal deforestation, burning, silting and non-compliance with environmental laws. The objective of this work was to evaluate the water quality of the Riacho Ouro in the city of Caxias / MA, through the analysis of the physical and ENCICLOPÉDIA BIOSFERA, Centro Científico Conhecer - Goiânia, v.14 n.25; p.1375 2017
} 
chemical parameters, to determine its framing and its suitability for its various uses. Two collections were carried out at eight pre-defined points in the dry period, evaluated through fourteen quality parameters: physical (temperature, $\mathrm{pH}$, conductivity, true color, turbidity, total and dissolved total solids) and Chemicals (nitrite, nitrate, ammoniacal nitrogen, total phosphorus, alkalinity, iron and total hardness) and compared with the resolution of CONAMA 357/05. It was verified that the waters of the Riacho Ouro are with slightly acidic $\mathrm{pH}$, being able to be influenced by the decomposition of the organic matter in the bed of the creek. The parameters total alkalinity and iron dissolved according to the references were outside the acceptance limit. The phosphorus content was above the specification, probably due to the agricultural activities carried out in the area. Nitrogen with its different forms indicates that the Riacho Ouro is free of some pollutants that interfere with the quality of water and the life of the aquatic community and the riverine population.

KEYWORDS: Environmental degradation, Water resources, Water pollution.

\section{INTRODUÇÃO}

Cada vez mais é preocupante as degradações ambientais oriundas de ações antropogênicas. Algumas regiões que haviam capacidade satisfatória de água, hoje sofrem com a escassez influenciadas pelo uso excessivo, assoreamento dos rios e baixa qualidade devido a poluição das fontes (VICTORINO, 2007). De acordo com o relatório anual de 2014 mais de um bilhão de pessoas não tem acesso a água potável, este mesmo documento cita também uma previsão para 2050 que 2.500 bilhões de pessoas fiquem sem água potável (MOURA, 2015)

As águas doces de escoamento superficial possuem uma fração mínima em relação às águas salgadas (WALDMAN, 2009). Do total volume de água, 97\% são marinhas e dos $3 \%$ restantes, $2 \%$ estão disponíveis em rios, lagos e águas subterrâneas (água doce) e 1\% estão em locais de difícil acesso presentes em neve, geleiras permanentes e vapores de água contida na atmosfera (ROCHA \& ROCHA, 2009).

O Brasil possui a maior rede hídrica com $17 \%$ de todo volume presente no planeta (ROCHA \& ROCHA, 2009). O estado do Maranhão segundo MARANHÃO (2011) citado por LEITE (2011) 97,2\% dos recursos hídricos maranhenses são subterrâneos e $2,8 \%$ superficiais.

Na visão de SÁNCHEZ (2008), a degradação ambiental de origem antrópica causa alterações nos processos ou funções que afetam a qualidade ambiental causando um impacto negativo aos recursos naturais. Nesta perspectiva, a degradação ambiental em águas superficiais é provocada por lançamentos de resíduos urbanos, industriais e agrícolas (VICTORINO, 2007). Conforme a autora, em países industrializados, que possuem legislação severa quanto a qualidade da água, se constata que é um problema recorrente. Também funciona como política de planejamento auxiliando a gestão de recursos hídricos como um termômetro que visa o acompanhamento dos processos dos recursos hídricos caracterizando-a de maneira qualitativa tendo como alvo o controle ambiental (GUEDES et al. 2012).

A avaliação da qualidade da água através de parâmetros e indicadores físicoquímicos é uma forma de identificar possíveis ações antrópicas e alterações naturais no meio aquático em decorrências de mudanças climáticas ou uma forma de estabelecer um índice de qualidade para os cursos de águas de acordo com sua classificação na legislação vigente (BRASIL, 2006). 
Justifica-se se o presente trabalho pela importância que o Riacho do Ouro serve para as comunidades que estão em seu entorno e o utilizam em várias atividades domésticas, inclusive para o consumo humano. BARROS et al. (2014), afirmam que a bacia do Itapecuru no município de Caxias no Maranhão possui maior volume em água e conta com inúmeros afluentes, tendo o riacho do Ouro como um dos mais importantes.

O presente estudo teve como finalidade avaliar a qualidade da água do Riacho Ouro no Município de Caxias/MA, através de análises de parâmetros físicos e químicos, visando a determinação do seu enquadramento e sua adequabilidade para seus diversos usos.

\section{MATERIAL E MÉTODOS}

\section{Caracterização da Área de Estudo}

O riacho do Ouro é um afluente do rio Itapecuru localizado na parte direita, nas coordenadas $-4^{\circ} 50^{\prime} 35.35^{\prime \prime} \mathrm{S},-43^{\circ} 15^{\prime} 9.18^{\prime \prime} \mathrm{O}$, (GOOGLE EARTH PRO 2016), com altitude $104 \mathrm{~m}$. A nascente do riacho Ouro está localizada na Cabeceira do Ouro e foz na localidade Raiz, ambos município de Caxias Maranhão, estende-se por mais de $10 \mathrm{Km}$ (Fig.1).

O município de Caxias no estado do Maranhão possui uma área territorial de $5.196,771 \mathrm{~km}^{2}$ com limites as cidades de Coelho Neto, São João do Sóter, Codó, Matões, Parnarama e Timon, índices pluviométricos 1.600 a $1.800 \mathrm{~mm}$, média anual de temperatura $24^{\circ} \mathrm{C}$.

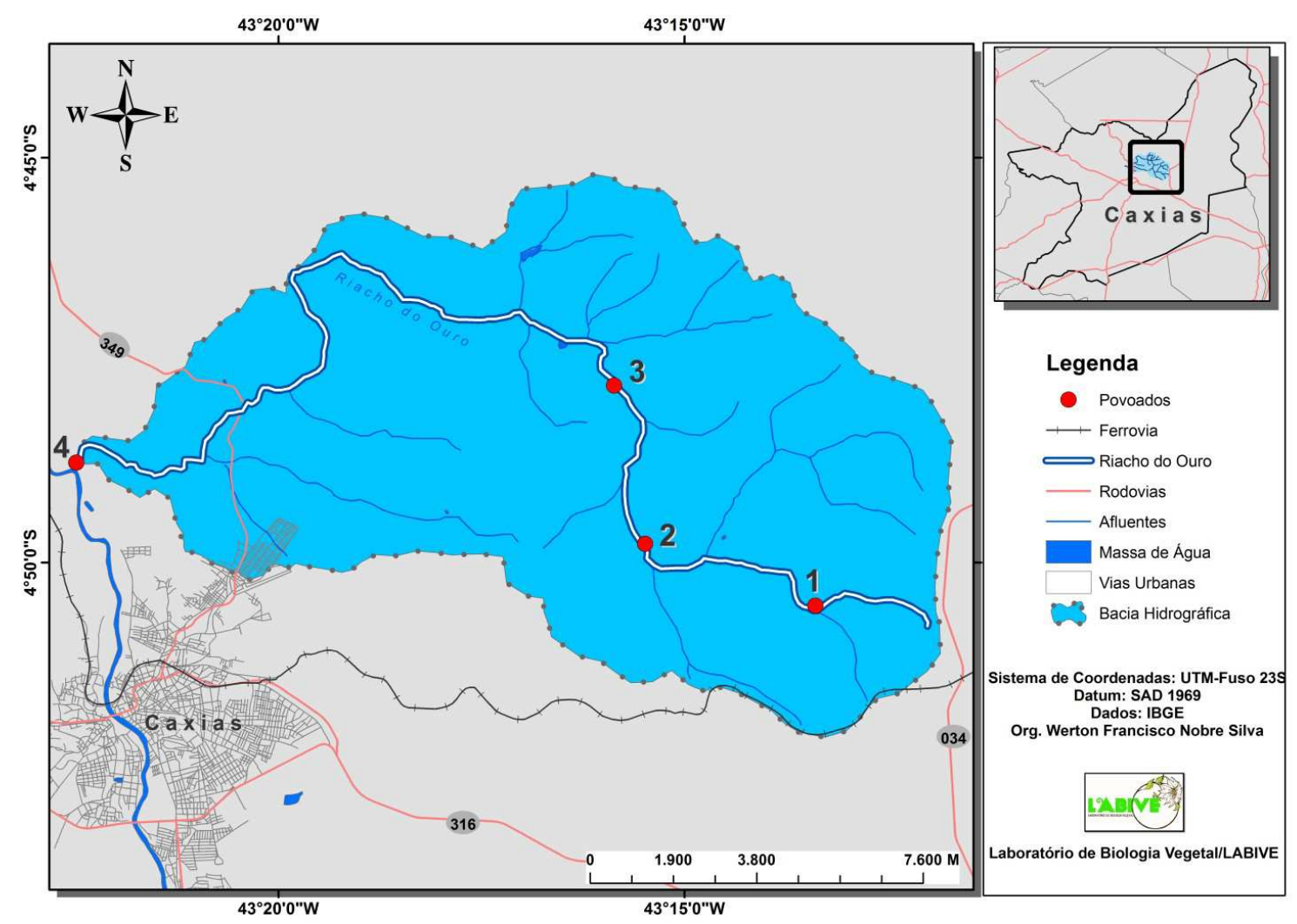

FIGURA 1. Mapa de localização da bacia hidrográfica do riacho Ouro,Caxias/MA. (1Povoado Cabeceira do Ouro, 2- Povoado Bacabalzinho, 3- Povoado Junco, 4- Povoado Raiz)

Fonte: IBGE, (2006); Organização: SILVA (2016). Definição dos pontos de amostragem 
Foram definidos quatro pontos de coleta para cada local, P1, P2, P3, P4 na nascente localizado no povoado Bacabalzinho (Fig. 2. A) e no médio curso nos pontos P5, P6, P7, P8 localizado no povoado Junco (Fig. 2.B). Os pontos de coleta foram definidos somente na região de nascente e médio curso de acordo com a existência de ilhas com volume significante de água, pois em função do período de estiagem o curso ficou interrompido em vários pontos do riacho do Ouro principalmente na região da desagua no rio Itapecuru.

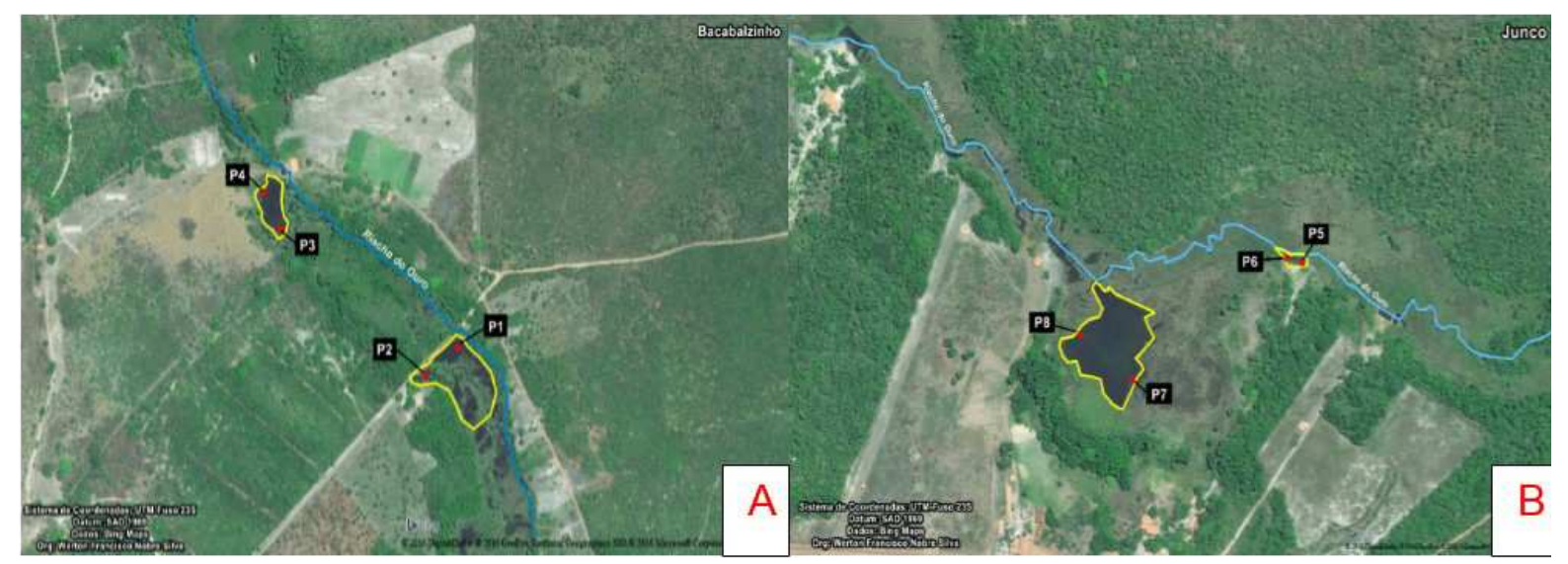

FIGURA 2. Mapa de localização dos pontos de amostragem no riacho Ouro, Caxias/MA. A. Região da nascente; B. Região do médio curso.

Fonte: BING MAPS, (2016); Organização: SILVA (2016).

\section{Coleta de dados}

Foram realizadas expedições aos pontos amostrados no período de seca durante os meses de outubro e novembro de 2016 para coleta de amostra de água para análise de parâmetros físico-químicos. A príncipio o resultado seria o comparativo de três pontos do riacho, nascente, médio curso e deságua ou foz, mas em função do período de estiagem foram realizadas coletas somente nos pontos de nascente e médio curso. A metodologia de coleta utilizada foi de acordo com o manual de procedimento de coleta e metodologia de análise de água da Companhia Energética de Minas Gerais (CEMIG, 2009).

As amostras de água foram coletadas manualmente com auxílio de garrafas PET com volume de dois litros, previamente identificadas, a aproximadamente um metro da margem e profundidade de $20 \mathrm{~cm}$.. As amostras foram acondicionadas em caixa de isopor com gelo afim de preservar as características físico-químicas da água, posteriormente, foram encaminhadas para o labotarório físico-químico, exceto para o parâmetro temperatura do ar e da água que foram realizadas no local.

As análises foram realizadas em triplicatas de acordo com padrões rigorosos para determinação quantitativas de parâmetros físco-químicos como o Standard Methods for the of Water and Wastewater (APHA, 1995).

\section{RESULTADOS E DISCUSSÃO}

Estão representados na Tabela 1 os resultados dos parâmetros físicoquímicos avaliados para determinação da qualidade da água do riacho do Ouro Caxias Maranhão comparados com a resolução do CONAMA no 357 de março de 2005.

TABELA 1. Resultados dos parâmetros fisíco-quimicos. 
CONAMA Outras

\begin{tabular}{|c|c|c|c|c|c|c|c|c|c|c|}
\hline \multirow[b]{2}{*}{ Parâmetros analisados } & \multicolumn{4}{|c|}{ Nhannantn } & \multicolumn{4}{|c|}{ Mádin nurkr } & \multirow{2}{*}{$\begin{array}{l}\text { CONAMA } \\
357 / 2005\end{array}$} & \multirow{2}{*}{$\begin{array}{l}\text { Outras } \\
\text { referências }\end{array}$} \\
\hline & $\mathrm{P} 1$ & $\mathrm{P} 2$ & P3 & $\mathrm{P} 4$ & P5 & P6 & $\mathrm{P7}$ & P8 & & \\
\hline Temperatura do ar $\left({ }^{\circ} \mathrm{C}\right)$ & 30 & 30 & 30 & 30 & 31 & 31 & 31 & 31 & & \\
\hline $\begin{array}{l}\text { Temperatura da água } \\
\left({ }^{\circ} \mathrm{C}\right)\end{array}$ & 26 & 26 & 28 & 28 & 27 & 27 & 27 & 28 & & \\
\hline $\mathrm{pH}$ & 6,3 & 6,3 & 6,2 & 6,2 & 7 & 7,2 & 6,4 & 6,4 & 6 a 9 & \\
\hline Condutividade $\left(\mu \mathrm{Scm}^{-1}\right.$ & 106 & 105 & 643 & 636 & 192 & 200 & 353 & 355 & & 500 a 800 \\
\hline $\begin{array}{l}\text { Cor verdadeira (mg Pt } \\
\left.\mathrm{L}^{-1}\right)\end{array}$ & 15 & 16 & 15 & 22 & 61 & 110 & 20 & 20 & 75 & \\
\hline Turbidez (UNT) & 5,4 & 1,2 & 3,4 & 4,4 & 7,5 & 7 & 30 & 32 & 40 & \\
\hline $\mathrm{ST}\left(\mathrm{mg} \mathrm{L}^{-1}\right)$ & 50 & 60 & 90 & 80 & 370 & 330 & 320 & 330 & & \\
\hline STD $\left(\mathrm{mg} \mathrm{L}^{-1}\right)$ & 10 & 10 & 10 & 10 & 30 & 20 & 20 & 30 & 500 & \\
\hline Nitrito $\left(\mathrm{mg} \mathrm{L}^{-1}\right)$ & $A$ & $A$ & $A$ & $A$ & $A$ & $A$ & $A$ & $A$ & 1 & \\
\hline Nitrato $\left(\mathrm{mg} \mathrm{L}^{-1}\right)$ & 0 & 0 & 0 & 0 & 0,8 & 0,6 & 0,1 & 0,1 & 10 & \\
\hline $\begin{array}{l}\text { Nitrogênio amoniacal } \\
\left(\mathrm{mg} \mathrm{L}^{-1}\right)\end{array}$ & $A$ & $A$ & $A$ & A & $A$ & A & $A$ & A & 3,7 & \\
\hline Fósforo total $\left(\mathrm{mg} \mathrm{L}^{-1}\right)$ & 0 & 0 & 0 & 0 & 1,6 & 2,4 & 2,7 & 2,3 & 0,1 & \\
\hline Alcalinidade $\left(\mathrm{mg} \mathrm{L}^{-1}\right)$ & 10 & 10 & 10 & 15 & 40 & 48 & 13 & 12 & & 30 a 500 \\
\hline Ferro $\left(\mathrm{mg} \mathrm{L}^{-1}\right)$ & 0,3 & 0,4 & 0,3 & 0,4 & 1,9 & 1,8 & 0,7 & 0,7 & 0,3 & \\
\hline Dureza total $\left(\mathrm{mg} \mathrm{L}^{-1}\right)$ & 28 & 31 & 30 & 30 & 8,6 & 10 & 18 & 18 & & 500 \\
\hline
\end{tabular}

\subsection{Temperatura}

Verificou-se que não houve variações significativas de temperatura do ar (média de $31^{\circ} \mathrm{C}$ ) e água (média $27^{\circ} \mathrm{C}$ ). Essas variações mínimas de temperatura do ar e água possibilitam aos corpos de água o equilíbrio nos processos biológicos da vida aquática (DALTRO FILHO; SANTOS, 2001, apud VASCO et al., 2011. A temperatura é um dos parâmetros importante para os processos físicos na solubilidade de gases químicos nas reações e biológico nas taxas de crescimento dos organismos aquáticos (ESTEVES, 1998).

De acordo com VON SPERLING (2007), a temperatura média dos ambientes aquáticos variam entre 22 a $30^{\circ} \mathrm{C}$ em território brasileiro, sendo um importante fator ecológico que pode influenciar uma diversidade de indivíduos aquáticos e a semelhança que pode existir entre a mesma e o teor de gases dissolvidos.

\section{$3.2 \mathrm{pH}$}

Os valores de $\mathrm{pH}$ dos diferentes pontos em comparação com a resolução do CONAMA 357/2005 para águas de classe 1, mantiveram-se de acordo com a norma vigente, com valores mínimo de 6,2 em P2 e P4 e máximo de 7,2 em P6 (Tabela 1). Dentro da escala de $\mathrm{pH}$, as águas do riacho Ouro estão em um padrão de neutralidade a levemente ácidas.

Esses resultados de $\mathrm{pH}$ neutros para levemente ácidos no Riacho do Ouro, são influenciados provavelmente por ações naturais, apesar de que foi constatado algumas ações antrópicas, tais como, desmatamento, queimadas, assoreamento, dentre outros, no decorrer de toda a extensão do riacho, mas que nenhuma destas podem ter influências em mudanças bruscas de $\mathrm{pH}$. 
. Portanto é provável que a influência dos valores encontrados de $\mathrm{pH}$ seja em decorrência da grande quantidade de plantas aquáticas no leito do riacho que contribui para decomposição de matéria orgânica, consequentemente com a produção de ácidos húmicos evidenciando-se pela própria cor amarelada da água (BRASIL, 2014).

Segundo ESTEVES (1998), a comunidade aquática interfere diretamente no $\mathrm{pH}$, onde o mesmo cita a assimilação de $\mathrm{CO}_{2}$ através de algas e macrófitas como constituintes deste processo. ESTEVES (2011) afirma que a redução do pH é causado pelo aumento da matéria orgânica e a própria constituição química do solo e as dissoluções de rochas.

\subsection{Condutividade}

Conforme análise da tabela 1 foi possível identificar grandes variações de condutividade entre os pontos de coletas, com resultado médio máximo de $639,5 \mu \mathrm{Scm}^{-1}$ para os pontos P3 e P4 e miníma de $105,5 \mu \mathrm{Scm}^{-1}$ para os pontos P1 e P2. Uma justificativa para essas variações pode está relacionado a vários fatores como a formação geológica, pois, segundo os autores ARCOVA; CICCO (1999); SOUZA; TUNDISI (2000); BASSOI; GUAZELLI (2004), ressaltam que áreas geologicamente pobres, ausência de fontes de poluição pontual, podem colaborar para baixa condutividade da água. Para ESTEVES (1998) condições de pH baixo e altas taxas de decomposição são fatores para acréscimo de condutividade, mas que nem sempre esses valores são altas concentrações de íons e sim substâncias ionizáveis que levam ao erro na determinação de condutividade e a elevação de resultado.

Os resultados de Condutividade foram comparados com ANZECC E KPDES (2010) com limite máximo de 500 a $800 \mu \mathrm{Scm}^{-1}$, pois a resolução do CONAMA 357/2005, não dar relevância para a variável, ESTEVES (2011), orienta que a condutividade é um fator prepoderante que pode subsidiar no processo de degradação de uma bacia de drenagem.

\subsection{Cor verdadeira}

De acordo com a tabela 1, o ponto 6 (Fig.3) foi o único que apresentou resultado superior ao permitido na resolução do CONAMA 357/ 2005 para água doce de classe 2. Esse resultado pode estar relacionado a alta taxa de decomposição de matéria orgânica, raízes, gravetos e folhas, em função da concentração excessiva de plantas aquáticas desencadeados no processo de eutrofização e consequentemente com a produção de substâncias húmicas, fortalecida pelo aparecimento da cor amarelada da água, características ocasionadas com a presença desse tipo de substâncias (UFRJ,2012).

\subsection{Turbidez}

De acordo com a Tabela 1, o resultado de turbidez no riacho do Ouro atendeu aos requisitos das normas do CONAMA de resolução 357/2005 para águas doces de classe 1. Constatou-se o aumento dos valores para os pontos P7 e P8 em relação aos outros, provavelmente pode ser influenciada pela presença de partículas arenosas suspensas. Para ESTEVES (1998), as partículas suspensas, como fitoplâncton e detritos orgânicos e inorgânicos são uma das principais características que elevam o resultado de turbidez. Os valores encontrados não irá comprometer a vida aquática uma vez que para a própria legislação vigente do CONAMA esse parâmetro de determinação de qualidade considera como limite máximo 100 UNT. 
3.6 Sólidos totais (ST) e sólidos totais dissolvidos (STD)

A resolução do CONAMA 357/2005 determina como parâmetro relevante para determinação da qualidade da água somente sólidos totais dissolvidos. Em relação aos pontos de amostragem citados na Tabela 1, verificou-se que todos os pontos estão dentro do limite aceitável da legislação vigente para sólidos totais dissolvidos. Constatou-se que também existe uma quantidade maior de partículas no médio curso quando comparados aos pontos da nascente.

Os altos valores para sólidos totais nos pontos de médio curso podem estar relacionados a devastação da mata ciliar e ao pequeno volume de água podendo carrear substâncias orgânicas e inorgânicas para o leito do riacho (BRASIL, 2014).

\subsection{Nitrito}

A Tabela 1, para o teste qualitativo de nitrito mostrou somente a presença ou ausência de nitrito para os diferentes pontos. Todos os resultados obtidos no riacho do Ouro foram ausentes estão dentro do limite de aceitação da resolução do CONAMA 357/ 2005 para águas doces de classe 1, tem como limite máximo 1,0 $\mathrm{mgL}^{-1}$.

Geralmente a presença de nitrito em águas é baixo devido a presença de oxigênio dissolvido que causa a sua instabilidade (ESTEVES, 1998). A concentração de nitrito em corpos hídricos também pode ser provocada por bactérias em condições anaeróbias estas oxidam o nitrato pela disponibilidade de oxigênio presentes na água, de acordo com as considerações NETO (2003). O fato de não existir indícios de poluição originadas de redes de esgotos e a própria instabilidade desse íon pode justificar a sua ausência em toda área de estudo.

\subsection{Nitrato}

Os resultados de Nitrato nos diferentes pontos de coleta atenderam a especificação do CONAMA 357/ 2005 que tem como limite o valor máximo de 10 $\mathrm{mg} / \mathrm{L}$. De acordo com a tabela 1, apresentaram teores de nitrato nos pontos de amostragem P5, P6, P7 E P8. A presença de nitrato pode estar relacionado ao uso marginal das terras para agricultura nas margens do riacho, com utilização de fertilizantes. De acordo com BAIRD (2002), o cultivo intensivo da terra facilita a oxidação para nitrato do nitrogênio reduzido presente na matéria orgânica decomposta pelo efeito da aeração e umidade.

\subsection{Nitrogênio amoniacal}

De acordo com a Tabela 1, os valores qualitativos de nitrogênio amoniacal foi ausente para todos os pontos. Deste modo, os resultados estão de acordo com a legislação vigente do CONAMA 357 / 2005 para águas doces de classe $1 \mathrm{com}$ pH $\leq$ 7,5 que tem como limite máximo $3,7 \mathrm{mg} \mathrm{L}^{-1}$.

Conforme os resultados apresentados o riacho do Ouro está ausentes para poluições de origem doméstica, de acordo com VASCO (2011), afirma que o nitrogênio amoniacal é um indicador de poluição orgânica doméstica.

Segundo SANTOS et al. (2001), a conservação dos recursos naturais deve ocorrer, tanto por causas ecológicas, quanto por questões doméstico, pois a sociedade mantém um grau de dependência para o seu próprio bem-estar pessoal e para todos.

\subsection{Fósforo total}


O resultado de fósforo total no riacho do Ouro foi diferente para a nascente e médio curso, sendo que na nascente os resultados encontram-se dentro das normas, enquanto que para o médio curso estes estão fora dos limites definidos pela resolução do CONAMA 357/ 2005 para água doce de classe 1. A geomorfologia dos pontos analisados basicamente são as mesmas, e isso diminui a probabilidade do aumento da concentração de fósforo total serem ocasionados de forma natural, onde as mesmas estão mais direcionadas para ações antropogênicas. De acordo com tabela 1, os pontos P5, P6, P7 E P8 foi constatada atividades agroindustriais e agropecuárias, no cultivo da cana-de-açúcar para a produção de cachaça artesanal, pastagem e suinocultura. Essas atividades podem gerar substâncias provenientes dos fertilizantes utilizados nas pastagens e nas plantações de cana-de açúcar e resíduos fecais oriundos da suinocultura, todos esses materiais podem chegar ao lençol freático ou serem carreados para o leito do riacho e contribuir positivamente para o aumento de fósforo total (ESTEVES, 1998).

Umas das evidências do aumento de fósforo nos pontos P5, P6, P7 E P8 foi o processo de eutrofização. Segundo ESTEVES (1998) o fósforo serve de nutriente e contribui positivamente para aumento do desenvolvimento de plantas, contribuindo para este processo. Nesses pontos foi verificada uma densidade alta de plantas no leito e nas margens do riacho e uma coloração amarelada fruto de processos de decomposição. Grande quantidade de populações de organismos pode afetar a vida aquática com o aumento do consumo de oxigênio e aumentando a quantidade de organismos anaeróbicos.

$\mathrm{Na}$ visão de RODRIGUES (2007), ações antrópicas podem comprometer a qualidade da água, provocando alterações como a redução do oxigênio dissolvido, aumento da turbidez, mudanças de $\mathrm{pH}$ e aumento quantidade de nitrogênio e fósforo. Por esta ótica, pode-se inferir que as alterações encontradas nestes pontos estão afetando a qualidade da água colaborando para o aumento da degradação ambiental do riacho e prejudicando a sobrevivência dos organismos aquáticos.

\subsection{Alcalinidade total}

O Conselho Nacional do Meio Ambiente CONAMA 357/ 2005 não estabelece alcalinidade total como parâmetro indicador de qualidade de águas superficiais. No entanto, MORAES (2008, apud COELHO, et al. 2015) citam a importância dos processos de decomposição de matéria orgânica e respiração de microrganismos valores de 30 a $500 \mathrm{mg} / \mathrm{L}$, nesse contexto somente os pontos P5 E P6 ficaram dentro dos limites aceitáveis com valores médios de $44 \mathrm{mg} \mathrm{L}^{-1}$, enquanto os demais pontos apresentaram resultados bem abaixo da referência citada e são considerados de acordo com CHAPMAM E KIMSTACK (1992, apud COELHO, et. al 2015) águas com baixo tamponamento e facilmente suscetíveis a mudanças de $\mathrm{pH}$.

\subsection{Ferro dissolvido}

A Tabela 1, apresenta o teor de ferro dissolvido para os diferentes pontos de amostragem no riacho do Ouro e comparados com a resolução do CONAMA $357 / 2005$ para água doce de classe 1. Dentre os pontos analisados constatou-se que somente dois pontos P1 e P3 ficaram dentro dos limites aceitáveis da legislação vigente. Os demais pontos obtiveram resultados fora do limite de aceitação. As variações de resultados entre os pontos de amostragem pode terem sido influenciados pelo o volume de água, uma vez que, quanto menor for o volume maior será a concentração e da própria constituição do tipo de solo, segundo IBGE (2015) na área de estudo predomina o solo do tipo latossolo amarelo e o mesmo já 
existe uma quantidade significativa de ferro dissolvido através do processo de intemperismo.

Apesar do teor de ferro no riacho do Ouro não atender a legislação vigente do CONAMA 357/ 2005, esses valores não apresentam danos à saúde da população usuária do recurso hídrico e nem para as populações aquáticas (BRASIL, 2014).

\subsection{Dureza total}

O parâmetro de dureza total não estar contido na resolução do CONAMA 357/ 2005. No entanto, os dados foram comparados com a portaria do Ministério da Saúde 518/2004 para águas com destinação para consumo humano, tendo como limite máximo aceitável $500 \mathrm{mg} \mathrm{L}^{-1}$.

De acordo com a tabela 1, os resultados obtidos de dureza total para o riacho do Ouro estão dentro do limite aceitável da legislação do Ministério da Saúde. Águas com concentração $<50 \mathrm{mg} \mathrm{L}^{-1}$ de $\mathrm{CaCO}_{3}$ são classificadas como brandas ou moles (BRASIL, 2014). O riacho do Ouro se encontra com média de $22 \mathrm{mg} \mathrm{L}^{-1}$ para variável dureza total.

\section{CONCLUSÕES}

De acordo com os resultados apresentados conclui-se que as ações antropogênicas foram determinantes para acréscimo de fosforo total. Enquanto que alcalinidade total pode favorecer mudanças de $\mathrm{pH}$, conforme recebimento de cargas de natureza ácidas ou básicas. Já para o teor de ferro dissolvido acima do padrão estabelecido pode estar associado às constituições do tipo de solo predominante na região.

Cor verdadeira acima do especificado em P6 aponta ações naturais influenciadas pela quantidade de material em decomposição no leito do riacho associados ao baixo volume de água

A avaliação da qualidade da água do riacho do Ouro serve para alertar os poderes públicos para tomada de decisões com vista a campanhas de conservação, principalmente as comunidades que estão no seu entorno.

\section{REFERÊNCIAS}

BARROS, V. L. L.; SILVA, P. J.; PEREIRA, L. C.; VALE, F. S. Rio Itapecuru: uma visão geoambiental em Caxias-MA. REVISTA HUMANA. Paço do Lumiar, V. 1, N, 2 , P. 104-119, 2014.

BASSOI, L. J.; GUAZELLI, M. R. Controle ambiental da água. in: Philippi, Jr., A., Romério, M. A.; Bruna, g. c. curso de gestão ambiental. Monole. Barueri, 2004. 1045p.

CIDADES. Disponível em: <http.www.ibge.gov.br>. Acesso em 01.12.2016.

COELHO.D.A, SILVA.A.R.S, CASTRO.T.O, SANTOS.R.C.G, PASSOS.A.S. Análise de alcalinidade total e concentração de carbono inorgânico em trechos urbanos de rios: o exemplo do rio santa rita, região sudoeste da Bahia. vi congresso brasileiro de gestão ambiental, Porto Alegre, 2015.

CONSELHO NACIONAL DO MEIO AMBIENTE (CONAMA). Resolução no 357 de 17 de março de 2005. Ministério do Meio Ambiente. 2005. 
ESTEVES, F. A. Fundamentos de limnologia. Interciência. Rio de Janeiro, 2011. P. 826.

ESTEVES. F.A. Fundamentos de limnologia. $2 \square$ Ed. Rio de Janeiro: Interciência, 1998.

GUEDES, H. A. S. et al. Aplicação da análise estatística multivariada no estudo da qualidade da água do rio pomba, $\mathrm{mg}$. Revista brasileira de engenharia agrícola e ambiental, p. 558-563, Campina Grande, 2012. Disponível em: <http://wwww.scielo.br/scielo.php?script=sci_arttext\&pid=S141543662012000500012 \&lng=en\&nrm=iso $>$. doi: 10.1590/S141543662012000500012

KPDES-KENTUCKY POLLUTANT DISCHARGE ELIMINATION SYSTEM. 2010. Conductivity and water quality. Disponível : <http://kywater.org/ramp/rmcond.htm.>

MINISTÉRIO DA SAÚDE. FUNDAÇÃO NACIONAL DE SAÚDE. Manual de controle da qualidade da água pata técnicos que trabalham em etas. Ministério da Saúde, Fundação Nacional de Saúde-Brasília: FUNASA, 2014.

MINISTÉRIO DA SAÚDE. Vigilância e controle da qualidade da água para consumo humano. Secretaria de Vigilância em Saúde. Brasília. 2006 P.212.

MINISTÉRIO DO PLANEJAMENTO, ORÇAMENTO E GESTÃO. Manual técnico de pedologia. 3.Ed. Instituto Brasileiro de Geografia e Estatística. Rio de Janeiro, 2015.

MINISTÉRIO DA SAÚDE. Portaria ms no 518 de 25 de março de 2004. Editora Ministério da Saúde. Brasília-DF, 2005

MOURA.A.J. A crise hídrica no Brasil. Água como elemento raro e caro. Water Crisis in Brazil: Water as a rare and expensive element. Facimed. 2015

NETO, M.S.S et al. Caracterização hidrogeoquímica da bacia do rio MansoCuiabá, MG. Acta limnológica brasiliensia. vol. 14, p. 14-36, 2003.

ROCHA, A. H.; ROCHA, C. J.; Introdução a química ambiental. 2 Ed. Porto Alegre, 2009.

RODRIGUES, E. Século xxi rumo ao desenvolvimento sustentável e a educação ambiental. Revista Bioética e Educação, Belo Horizonte: Bio consulte, no. 01, 2007, p. 179-190 (Universidade Federal de Lavras -UFLA)

SÁNCHEZ, L. E. Avaliação de impacto ambiental: conceitos e métodos. São Paulo: Oficina de textos, 2008.

SANTOS, J. E.; NOGUEIRA, F.; PIRES, J. S. R.; OBARA, A. T.; PIRES, A. M. Z. C. $R$. The value of the ecological station of jatai's ecosystem services and natural capital. Rev. Bras. Biol, São Carlos, V. 61, n. 2, p. 171-190, 2001. Disponível em: <http://www.scielo.br/scielo.php?script=sci_arttext\&pid=s0034-

$71082001000200002 \&$ Ing=en\&nrm=iso $>$. doi: $10.15900 / s 0034-71082001000200002$ 
SECRETARIA DE ESTADO E MEIO AMBIENTE E RECURSO NATURAIS. Plano de ação para prevenção e controle do desmatamento e das queimadas no estado do maranhão. decreto no 27. 317, 14 de abril, 2011, São Luís, 2011.

SOUZA, A. D. G.; TUNDISI, J. G. Hidrogeochemical comparative study of the jaú and jacaré-guaçu river watersheds São Paulo, Brasil. Revista brasileira de Biologia, São Carlos, v.60, n. 4, p. 563-570, 2000. Disponível em: $<$ http://www.scielo.br/scielo.php?script=sci_arttext\&pid=S003471082000000400004\& Ing=en\&nrm=iso > . doi: 10.15900/S0034-71082000000400004

UFRJ. Cor da água. Rio de Janeiro, 2012. Disponível em: $<$ http//www.ufrrj.br/institutos/it/de/acidentes/cor.htm.>

VASCO, A.N.; BRITTO, F.B.; PEREIRA, A.P.S.; MÉLL JÚNIOR, A.V.; GARCIA, C. A.; NOGUEIRA, L.C. Avaliação espacial e temporal da qualidade da água na sub-bacia do rio Poxim, Sergipe, Brasil. ambi-agua, Taubaté, v. 6, n.1, p.118130,2011. Disponível em: <http://ambi-agua.net/seer/index.php/ambiagua/article/view/592> doi: 10.4136/ambi-agua.178

VICTORINO, C. J. A. Planeta água morrendo de sede: Uma visão analítica na metodologia do uso e abuso dos recursos hídricos. Porto Alegre: Edipucrs, 213p. 2007.

VON SPERLING, M. Estudos e modelagem da qualidade da água de rios. Princípios do tratamento biológico de águas residuárias. 3.ed. Belo Horizonte: UFMG, v. 7, p. 588, 2007.

WALDMAN, M. Tríade de água, lixo e energia: Essencialidade dos recursos hídricos. Curso de formação ambiental, São Bernardo do Campo, 2009 